CLINICAL STUDY

\title{
Identification of several novel non-p.R132 IDH1 variants in thyroid carcinomas
}

\author{
Jefferson Pessoa Hemerly, André Uchimura Bastos and Janete M Cerutti \\ Laboratório Bases Genéticas dos Tumores da Tiroide, Disciplinas de Genética e Endocrinologia, Universidade Federal de São Paulo, Rua Pedro de Toledo 669, \\ $11^{\circ}$ andar, 04039-032 São Paulo, SP, Brazil
}

(Correspondence should be addressed to J M Cerutti; Email: j.cerutti@unifesp.br)

\begin{abstract}
Context: Somatic mutations at residue R132 of isocitrate dehydrogenase 1 (IDH1) were recently discovered in gliomas and leukaemia at a high frequency. IDH1 is a metabolic gene, and the R132 mutations create a new enzymatic activity.

Objectives: To determine whether IDH1 had somatically acquired mutations in thyroid carcinomas. Design: Exons 4 and 6 of IDH1 were sequenced in a large panel of thyroid tumours $(n=138)$ and compared with the patients normal DNA $(n=26)$. We also correlated IDH1 mutations with clinical-pathological data and BRAF and RAS mutational status.

Results: We identified four novel and two previously described non-synonymous variants in thyroid carcinomas, which were absent in benign tumours and paired normal thyroid. Although IDH1 variants occurred at higher frequency in follicular thyroid carcinomas, follicular variant of papillary thyroid carcinoma (PTC) and undifferentiated thyroid carcinomas than the observed variants in classical PTC (15/72 vs 3/37), it was not significant $(P=0.1)$. Sequence alignment across several species shows that all IDH1 genetic alterations occurred at evolutionarily conserved residues located within the active site, and therefore, are likely to affect protein function. Unlike other tumours, IDH1 and BRAF or RAS mutations are not mutually exclusive. There was no association between IDH1 mutational status and clinical characteristics.

Conclusion: IDH1-acquired genetic alterations are highly prevalent in thyroid carcinomas (16\%). Our findings not only extend our understanding of the molecular mechanism underlying pathogenesis of thyroid tumours, but also emphasize the biological differences between tumour types. Those tumours with IDH1 mutations might benefit from therapies that exploit this alteration.
\end{abstract}

European Journal of Endocrinology 163 747-755

\section{Introduction}

In the last three decades, thyroid cancer incidence has significantly increased worldwide (1). Most of the thyroid tumours of follicular cell origin are subdivided into the benign follicular thyroid adenoma (FTA) and the malignant follicular thyroid carcinoma (FTC) and papillary thyroid carcinoma (PTC). PTC is the most prevalent carcinoma subtype, accounting for about $80 \%$ of all thyroid cancers. FTC and its variant Hürthle cell carcinoma (HCC) represent $5-10 \%$ of thyroid cancers. In the last years, our knowledge about the molecular mechanism associated with the pathogenesis of thyroid cancer has increased. At the moment, wellestablished molecular events that have been correlated with the pathogenesis of PTC include activating mutations of RAS/BRAF or rearrangement of RET, both of which activate the MAPK pathway (2-4). Targeted therapy for tumours with mutations along the MAPK signalling pathway has been currently evaluated for thyroid carcinoma.
There has been an extensive effort over the last few years to identify FTC-associated mutations that can be used as diagnostic and/or prognostic marker and new target for therapy. PAX8/PPARG rearrangement, activating mutation in $R A S$ and inactivating mutation or loss of PTEN were initially associated with pathogenesis of FTC, but were also described in FTA (5-9). Therefore, less is known about the molecular events associated with FTC.

Cancer genes have been identified by several different and complementary strategies. A systematic analysis of breast, colon and glioblastoma multiforme (GBM) cancer genome defined the genetic landscape of these tumour types $(10,11)$. Important points have emerged from these analyses. First, the authors identified a subset of candidate cancer genes (CAN genes) that were most likely to have subjected to mutational selection during tumorigenesis (driver mutations). Second, the list of CAN genes includes a large number of genes not previously known to be linked to human cancer. 
Third, there is a substantial difference in the panel of CAN genes for each of these cancer types.

How the insights from different cancer genomes can be applied to thyroid cancer? In other words, how these studies can help us to identify the thyroid CAN genes? Interestingly, several genes previously shown to be mutated in thyroid carcinomas were found to be among the most frequently altered GBM CAN genes, such as PIK3CA, PTEN, RB, TP53, CDK2A and EGFR (9, 12-15). More importantly, the comprehensive analysis identified isocitrate dehydrogenase 1 (IDH1), an unpredicted cancer gene, as the most frequently mutated gene in GBMs (11). Subsequent studies of targeted IDH1 gene sequencing confirmed a recurrent mutation that affected the amino acid 132 of IDH1 (p.R132) in secondary glioblastoma (16). Therefore, an obvious question that arises is whether IDH1 can be mutated in thyroid tumours.

A following study investigated IDH1 mutations in a panel of solid tumours and cell lines (17). No mutations were identified in the other tumours types, including PTC and medullary thyroid carcinoma (MTC). Given that thyroid tumours are classified according to histological subtypes and clinical presentation, it remains uncertain whether IDH1 mutations may play a role in pathogenesis of other thyroid tumour subtypes.

We assessed here the mutational status of IDH1 in a large set of thyroid tumours and paired normal thyroid (NT) samples. This mutational attempt leads to the identification of four novel and two previously described non-synonymous variants in thyroid carcinomas, which were not identified in the DNA isolated from matched normal tissues and benign lesions. Although there is a trend in a higher frequency of IDH1 mutations in FTC and its variant and in follicular variant of PTC (FVPTC) than in classical PTC, further analysis using a large panel of samples will clarify this issue. Although BRAF gene fusion and IDH1 mutation were mutually exclusive in brain tumours, IDH1 mutation was co-presented with BRAF V600E or RAS mutations in thyroid carcinomas.

\section{Materials and methods}

\section{Samples}

A total of 164 thyroid specimens were obtained from patients, with their informed consent, undergoing thyroid surgery at Hospital São Paulo, Universidade Federal de São Paulo. Tissue specimens were frozen immediately after surgical biopsy and stored at $-80^{\circ} \mathrm{C}$ until use. Final histological classifications were obtained from paraffin-embedded sections and comprised 23 benign (12 FTA and 11 Hürthle cell adenoma (HCA)) and 115 malignant (7 HCC, 21 FTC, 37 PTC, 44 FVPTC, 3 undifferentiated thyroid carcinoma (UTC) and 3 MTC). Additionally, 26 NT tissues were tested, 16 were obtained from patients who were IDH1 positive. The study of patient tissues was conducted in accordance with the Declaration of Helsinki.

\section{DNA isolation, PCR amplification and direct sequencing}

DNA was isolated from thyroid samples using the standard phenol/chloroform procedure. DNA (200 ng) was amplified in $25-\mu \mathrm{l}$ PCRs containing $10 \mu \mathrm{mol} / \mathrm{l}$ of each specific primer, $10 \mathrm{mmol} / \mathrm{l}$ Tris- $\mathrm{HCl}(\mathrm{pH} 8.3)$, $50 \mathrm{mmol} / \mathrm{l} \mathrm{KCl}, 200 \mu \mathrm{mol} / \mathrm{l} \mathrm{dNTP}, 1.5 \mu \mathrm{mol} / \mathrm{l} \mathrm{MgCl}_{2}$ and $0.2 \mathrm{U}$ Taq DNA polymerase (Invitrogen) in a $25-\mu \mathrm{l}$ final volume. The PCR was performed as follows: 40 cycles of a three-step programme: $94{ }^{\circ} \mathrm{C}$ for $45 \mathrm{~s}$, annealing temperature for $20 \mathrm{~s}$ and $72{ }^{\circ} \mathrm{C}$ for $20 \mathrm{~s}$. The primer sequences to amplify exons 4 and 6 of the IDH1 gene, annealing temperatures and products sizes are detailed in Supplementary Table 1, see section on supplementary data given at the end of this article.

PCR products were resolved by electrophoresis, purified using the Concert Rapid PCR Purification System and submitted to direct sequencing using the Big Dye Terminator Cycle Sequencing Kit (Applied Biosystems, Foster City, CA, USA). Each sample was

A Non-synonymous variants

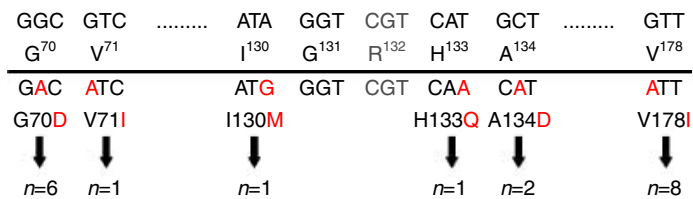

B

Prevalence of non-synonymous variants

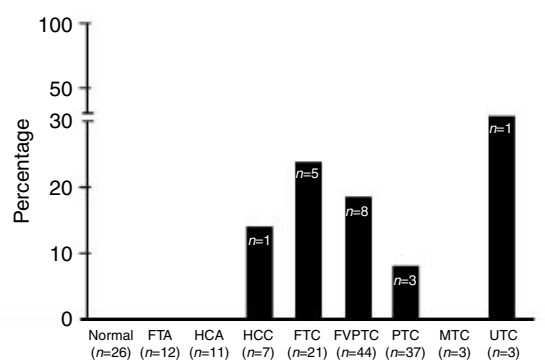

Figure 1 Somatic genetic alterations affecting IDH1 detected in thyroid carcinomas. (A) The nucleotide and amino acid changes are listed alongside the number of mutated samples. Arrows indicate the novel (G70D, I130M, H133Q and A134D) and previously described (V71I and V178I) variants. (B) Prevalence of IDH1 non-synonymous variants in different thyroid tumour subtypes and normal thyroid samples. Absolute numbers for each tumour subtype are stated in individual bars. FTA, follicular thyroid adenoma; HCA, Hürthle cell adenoma; HCC, Hürthle cell carcinoma; FTC, follicular thyroid carcinoma; PTC, papillary thyroid carcinoma; FVPTC, follicular variant of papillary thyroid carcinoma; MTC, medullary thyroid carcinoma; and UTC, undifferentiated thyroid carcinoma. Full colour version of this figure available via http://dx.doi.org/10. 1530/EJE-10-0473. 
sequenced at least twice and in both directions. Each mutation was confirmed by a second PCR and sequencing in both directions.

\section{Multiple amino acid sequence alignment}

Amino acid sequence alignment of IDH1 from five species was obtained from NCBI database (http://www. ncbi.nlm.nih.gov/protein/) as follows: Homo sapiens (GI: 49168486), Bos taurus (GI: 74354744), Mus musculus (GI: 57242927), Rattus norvegicus (GI: 13928690) and Canis lupus (GI: 89573987). These sequences were compared using a computer-based multiple sequence alignment programme: CLC Sequence Viewer 6.0 (CLC bio A/S, Katrinebjerg, Denmark).

\section{BRAF VGO0E and RAS mutational status in IDH1-positive thyroid carcinomas}

BRAF V600E mutation was investigated as previously described (3). Mutations at codon 61 of NRAS and codons 12, 13 and 61 of the HRAS and KRAS were analysed by direct sequencing of PCR products as aforementioned. The primer sequences to amplify $B R A F$ and RAS genes, annealing temperatures and products sizes are detailed in Supplementary Table 1.

\section{Statistical analysis}

The correlation between IDH1 mutational status, clinicopathological (age, gender, tumour size, extrathyroidal invasion and presence of metastasis) and histological variants was determined using Fisher's exact test. Data analysis was performed using StatView 4.5 software (Abacus Concepts Inc., Berkeley, CA, USA). A $P$ value $<0.05$ was considered statistically significant.

\section{Results}

\section{Prevalence of IDH1 non-synonymous variants in thyroid carcinomas}

We screened a large number of benign and malignant thyroid tumours for the presence of IDH1 mutation. A total of six non-synonymous variants were identified in 18 out of 115 thyroid carcinomas $(16 \%)$, which were absent in benign lesions (0/23; Fig. 1 and Table 1). Paired NT tissues were available from $16 / 18$ patients with IDH1 mutations. Therefore, we tested whether the non-synonymous variants were somatically acquired. No IDH1 genetic alterations were identified in paired NT tissues $(n=16)$ and other NT samples $(n=10)$ tested, indicating that the IDH1 was somatically acquired (Figs 2 and 3).

An interesting finding of this study is that a higher prevalence of non-synonymous variants was observed in FTCs, HCC, FVPTCs and UTC than in classical PTC $(15 / 72$ vs $3 / 37$; $P=0.1$; Fig. 1 and Table 1$)$. Additional analysis, using a bigger set of sample, is needed to clearly demonstrate whether IDH1 mutations preferentially accumulate in specific tumour subtypes.

\section{Four novel IDH1 variants in thyroid carcinomas}

Among the six non-synonymous changes identified in this study, four novel non-R132 variants located within exon 4 of IDH1 are described. A G70D substitution (GGC>GAC) was found in six thyroid carcinomas. The I130M (ATA $>$ ATG $)$ and H133Q (CAT $>$ CAA $)$ substitutions were observed only in FTC. Finally, an A134D substitution (CGC > CAT) was observed in two cases of FVPTC (Fig. 2). All mutations were somatic,

Table 1 Isocitrate dehydrogenase 1 (IDH1) variants in thyroid carcinomas and mutational status of $B R A F$ and RAS genes.

\begin{tabular}{|c|c|c|c|c|c|c|}
\hline $\begin{array}{l}\text { Tumour } \\
\text { ID }\end{array}$ & Diagnosis & $\begin{array}{l}\text { Amino } \\
\text { acid }\end{array}$ & $\begin{array}{l}\text { BRAF V600E } \\
\text { mutation }\end{array}$ & $\begin{array}{l}\text { NRAS } \\
\text { mutation }\end{array}$ & $\begin{array}{l}\text { HRAS } \\
\text { mutation }\end{array}$ & $\begin{array}{l}\text { KRAS } \\
\text { mutation }\end{array}$ \\
\hline 1 & $\mathrm{PTC}^{\mathrm{a}}$ & G70D & No & No & No & No \\
\hline 2 & $\mathrm{PTC}^{\mathrm{a}}$ & G70D & Yes & No & No & No \\
\hline 3 & $\mathrm{HCC}^{\mathrm{a}}$ & G70D & No & No & No & No \\
\hline 4 & $\mathrm{FTC}^{\mathrm{a}}$ & I130M & No & No & No & No \\
\hline 5 & $\mathrm{FTC}^{\mathrm{a}}$ & G70D & No & No & No & No \\
\hline 6 & $\mathrm{FTC}^{\mathrm{a}}$ & $\mathrm{H} 133 \mathrm{Q}$ & No & No & No & No \\
\hline 7 & FVPTC $^{a}$ & A134D & No & Q61K & No & No \\
\hline 8 & FVPTC $^{a}$ & A134D & No & No & No & No \\
\hline 9 & FVPTC $^{a}$ & G70D & Yes & No & No & No \\
\hline 10 & FVPTC $^{a}$ & G70D & Yes & No & No & No \\
\hline 11 & $\mathrm{PTC}^{\mathrm{a}}$ & V178I & Yes & No & No & No \\
\hline 12 & UTC & V178I & No & No & No & No \\
\hline 13 & FTC & V178I & No & No & No & Q61R \\
\hline 14 & $\mathrm{FTC}^{\mathrm{a}}$ & V178I & No & No & No & No \\
\hline 15 & FVPTC $^{a}$ & V71I and V178I & Yes & No & No & No \\
\hline 16 & FVPTC $^{a}$ & V178I & No & No & No & No \\
\hline 17 & FVPTC $^{a}$ & V178I & No & No & No & No \\
\hline 18 & FVPTC $^{a}$ & V178I & No & No & No & No \\
\hline
\end{tabular}

${ }^{\text {a }}$ Thyroid tumours and paired normal thyroid tissues evaluated for $I D H 1$ mutation. 
A
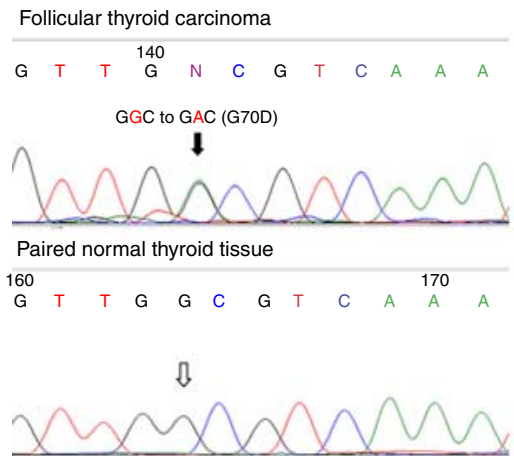

B

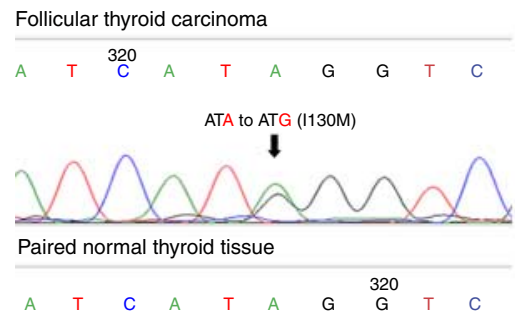

$\sqrt{n}$

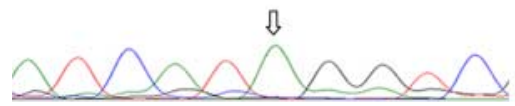

C
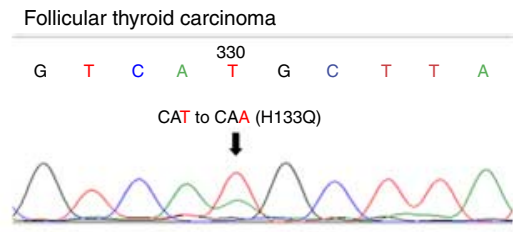

Paired normal thyroid tissue
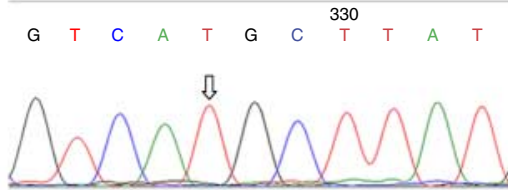

D

Follicular variant of papillary thyroid carcinoma
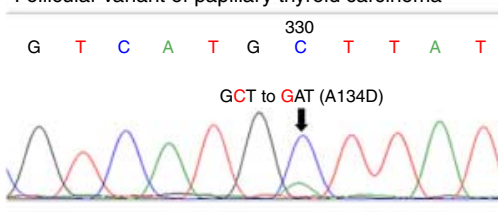

Paired normal thyroid tissue
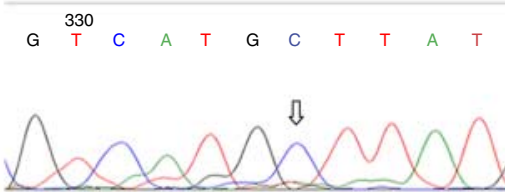

Figure 2 Illustration of novel IDH1 variants detected in FTC $(A-C)$ and follicular variant of papillary thyroid carcinoma (D). Mutations are detected in DNA from tumour (top), but they are absent in the DNA from paired normal thyroid tissue (bottom). Black arrows indicated the location of heterozygous missense mutation in tumours. White arrows indicated the matching location in paired samples. Full colour version of this figure available via http://dx.doi.org/ 10.1530/EJE-10-0473. as determined by analysis of DNA isolated from NT tissues from patients harbouring the IDH1 mutations.

Two non-synonymous changes identified in our study were previously described in the NCBI database as SNPs (base http://www.ncbi.nlm.nih.gov/projects/SNP). The non-synonymous variant V71I (rs73070954; GTC $>$ ATC) was identified in a FVPTC. The V178I (rs342) $8846 ;$ GTT $>$ ATT) was the most prevalent variant found in thyroid carcinomas (Table 1 and Fig. 3).

Interestingly, most of other studies in the literature refer V71I as a potential new mutation (17-19) (Table 2). Although the authors did not explore the prevalence of this variant in the DNA from paired normal samples, this variant was found in different tumour subtypes and cell lines. Given that exon 6 of IDH1 (V178I) is not commonly investigated, the prevalence of this mutation in different population and the functional role of this variant are still unclear (Table 2).

Whether these variants provide the cell with a selective advantage and are more likely to be driver mutation needs further investigation.

\section{Silent mutations of IDH1 gene in thyroid carcinomas}

We also identified two synonymous variants within exon 4 of IDH1 gene in thyroid carcinomas. The previously reported G105G (rs11554137) was
A Non-synonymous variants

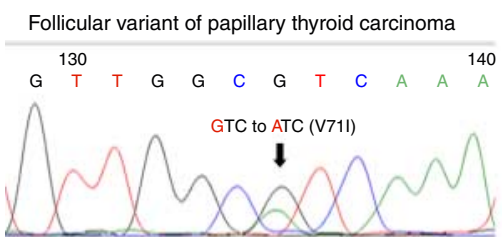

B Synonymous variants

Follicular variant of papillary thyroid carcinoma
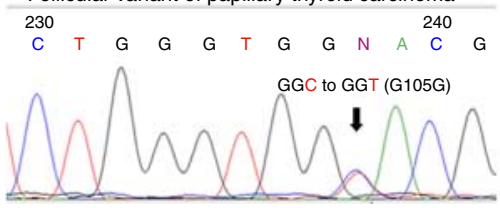

Follicular variant of papillary thyroid carcinoma

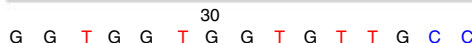

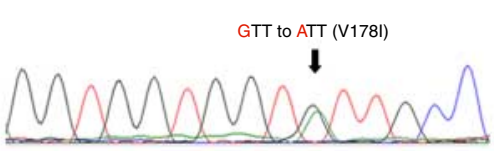

Follicular thyroid carcinoma

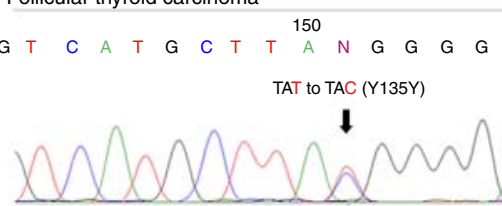

Figure 3 Illustration of IDH1 nonsynonymous variants $(A)$ and synonymous variants $(B)$ detected in thyroid carcinoma. Black arrows indicated the location of heterozygous missense mutation in tumours. Full colour version of this figure available via http://dx.doi.org/10.1530/ EJE-10-0473. 
Table 2 Prevalence of V71I and V178I variants in different tumour subtypes and carcinoma cell lines.

\begin{tabular}{|c|c|c|c|c|c|}
\hline \multirow[b]{2}{*}{ References } & \multirow[b]{2}{*}{ Tumour subtype } & \multicolumn{2}{|c|}{ V71I } & \multicolumn{2}{|c|}{ V178I } \\
\hline & & No & $\%$ & No & $\%$ \\
\hline \multirow[t]{2}{*}{ Our study } & Malignant tumours (PTC, FVPTC, FTC, HCC, UTC and MTC) & $1 / 115$ & 0.8 & $8 / 115$ & 7 \\
\hline & Benign tumours (FTA and HCA) and normal thyroid & $0 / 49$ & 0 & $0 / 49$ & 0 \\
\hline \multirow[t]{2}{*}{$(17)$} & $\begin{array}{l}\text { GBM, GIST, bladder, breast, colon, lung, melanoma, ovary, } \\
\text { pancreas, prostate, PTC and MTC }\end{array}$ & $0 / 672$ & 0 & NA & \\
\hline & Cancer cell lines & $1 / 84$ & 1.1 & NA & \\
\hline (18) & AML & $3 / 358$ & 0.8 & NA & \\
\hline (38) & AML & $11 / 257$ & 2.1 & NA & \\
\hline \multirow[t]{2}{*}{ (19) } & FTC and UTC & $2 / 38$ & 5.2 & NA & \\
\hline & Thyroid cancer cell lines & $0 / 12$ & 0 & NA & \\
\hline
\end{tabular}

NA, not available; GIST, gastrointestinal stromal tumour; AML, acute myeloid leukaemia. Paired normal tissues are not available for most studies.

described in six thyroid carcinomas and in two FTA. Although they were not found in corresponding NT tissue, in our study, the G105G variant was not identified as a cancer/disease-associated variant. Interestingly, however, the G105G silent mutation co-occurs with V178I non-synonymous variant in several thyroid carcinomas. Whether it is associated with worst prognosis needs further investigation. The G105G variant has been associated with inferior outcome in acute myeloid leukaemia (AML) (20), although it was found in normal controls in a prevalence of $11 \%$. The novel Y135Y variant (TAT $>$ TAC ) was found in a FTC (Fig. 3). The biological significance of this finding is unclear.

\section{Structure-based sequence alignment revealed that new mutations are located in highly conserved residues}

The structure-based sequence alignment of human IDH1 with different species showed that G70D, I130M, H133Q and A134D mutations are located in residues strictly conserved and close to substrate-binding site $(21,22)$ (Fig. 4). The G70D mutation represents the change from a non-polar to a polar negatively charged amino acid, which has an additional carboxyl group.
Although I130M represents a change from a non-polar to another non-polar amino acid, methionine is highly hydrophobic and includes a non-polar methyl thioether group at the terminus of its hydrocarbon chain. H133Q represents the change from a positively charged amino acid with an imidazole group to a polar and uncharged amino acid with a hydrophilic amide group. A134D represents the change from a non-polar to a polar negatively charged amino acid with an additional carboxyl group. Given that these changes occurred at amino acids are widely conserved among different species and close to the R132 residue, which amino acid exchanges rend the enzyme inactive through a dominant-negative manner, our findings suggest that the new mutations described here potentially affect IDH1 function. Whether the mutations represent a loss of enzyme activity needs further investigations. Likewise, the novel variants, the previously described variants occurred at amino acids, are widely conserved among different species (Fig. 4).

\section{IDH1 mutation and clinical features}

No association was found between IDH1 mutation and age, gender, tumour size, extra-thyroidal invasion and presence of metastasis.

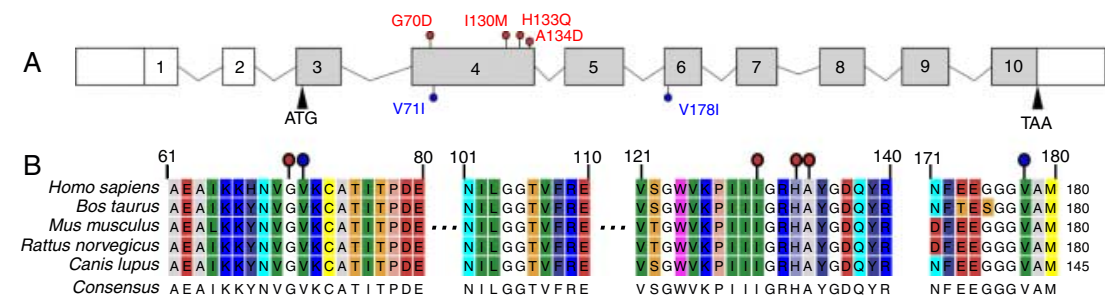

Figure $4 I D H 1$ variants detected in thyroid carcinomas and structure sequence alignment. (A) Schematic diagram of the IDH1 gene and corresponding location of novel (red mark) and previously described (blue mark) non-synonymous variants identified in this study. (B) Structure-based sequence alignment of human IDH1 protein with those from different species. Multiple sequence alignment across several species shows blocks with high levels of conservation. IDH1 novel mutations and non-synonymous variants occur at evolutionarily conserved residues. The alignment was drawn with CLC Sequence Viewer 6.0 (39). Full colour version of this figure available via http://dx. doi.org/10.1530/EJE-10-0473. 


\section{BRAF and RAS mutational status in IDH1-positive thyroid carcinomas}

As BRAF-KIAA1549 gene fusion and IDH1 mutation were mutually exclusive in pilocytic astrocytoma (23), we tested whether IDH1 and BRAF V6OOE mutation, the most prevalent mutation found in classical PTC and in FVPTC $(3,24)$, were co-presented in thyroid tumours. We found that BRAF V6OOE co-occurs in 2/3 IDH1-mutated subgroup of classical PTC and in 3/8 IDH1-mutated FVPTC (Table 2). Whether IDH1 mutation is associated with tumour progression needs further investigation.

Given that RAS mutations are commonly found in FTA, FTC and in a small subset of PTCs where there is no overlapping between BRAF V6OOE and RAS mutations, we additionally investigated whether there is an overlapping in IDH1 and RAS mutations in thyroid carcinomas. Although most of IDH1-positive tumours were negative for $R A S$ mutations, two thyroid carcinomas presented both RAS and IDH1 mutations (Table 2). All together, we observed that there was an overlap between RAS or BRAF and IDH1 mutation.

\section{Discussion}

We identified six non-synonymous changes in IDH1 gene in a panel of 164 thyroid samples. There were four novel non-p.R132 IDH1 variants and two previously described non-synonymous variants. The non-synonymous changes identified here were not identified in matched thyroid normal samples, suggesting that they were somatically acquired. Remarkably, IDH1 mutations were highly prevalent in FTC, its variant and in FVPTC, whereas they were not identified in the benign FTA and its variant. Importantly, a bigger set of sample is needed to determine whether IDH1 mutations may preferentially accumulate in specific tumour subtypes.

Somatic mutations at residue R132 of IDH1 were observed in gliomas and leukaemias at a high mutation rate $(11,25)$. Differently from two-hit model for tumour suppressor genes, it was demonstrated that molecules of IDH1 mutant dominantly inhibit the normal activity of wild-type IDH1 by forming a catalytically inactive heterodimer (26). Although IDH1 mutants lose their normal activity in tumours, it was shown that the mutants gain a novel enzymatic activity that generates 2-hydroxyglutarate (2HG). The new gain-of-function activity of the tumour-derived IDH1 mutants correlates with high levels of 2HG, which was 100-fold higher in gliomas harbouring R132 IDH1 mutations than in tumours with wild-type IDH1. It has been suggested that the excess of this 'onco-metabolite' has potential tumour-supporting actions and contributes to the pathogenesis and malignant progression of glioma $(22,27)$. Recently, it was demonstrated that IDH1 mutation significantly increases the 2HG in AML (28).
Additional evidences for the role of IDH enzymes in the pathogenesis of tumours came from studies that identified R172 IDH2 mutation in gliomas (16), which is analogous to IDH1 R132 and also increases the intracellular levels of 2HG (29). Other neomorphic allele has also been described in AML. Intriguingly, the R140Q mutation, equivalent to R100 in IDH1, was more prevalent than the $\mathrm{R} 132$ allele of IDH1 or the R172K allele of IDH2. These findings highlight the fact that non-p.R132 and non-p.R172 mutations play an important role in the pathogenesis of tumours.

We showed that all mutants identified in this study occurred in highly conserved residues. Amino acid residues forming catalytic subsite of the active site of enzymes are always highly conservative (30). In fact, glycine $(\mathrm{G})$, aspartic acid (D) and histidine (H) amino acids are among the most frequent conservative residues in enzymes. The changes described here, which are located within the active site and lead to significant changes in amino acid structure, are likely to affect protein function. Although sequence conservation has been utilized, methods for measuring the functional importance of individual amino acids, in vitro and in vivo analyses are still needed to determine the biological effects of the novel IDH1 variants identified in this study.

The non-synonymous V71I variant was identified in a FVPTC. Considering that we did not find this allele in normal matched sample and any of other benign lesions evaluated, our findings suggest that this variant is most likely to be relevant for pathogenesis of thyroid carcinoma. Interestingly, this variant was previously identified in the plasma myeloma cell line RPM1-8226. Given that a normal matched sample was not available and this variant was not identified in any of other 672 tumours and 84 cell lines, the authors suggested that it is either a very rare SNP or novel IDH1 mutation (17). Additionally, while this manuscript was in preparation, this variant was described in one case of FTC and UTC. Although paired NT was not evaluated for IDH1 mutations, the authors suggested that V71I variant was associated with pathogenesis of FTC (19). Interestingly, the authors described a non-p.R132 mutation in one UTC. The mutation G123R reduced the IDH1 activity at similar levels of R132H.

The non-synonymous acquired variant V178I, located in exon 6 of IDH1, was the most prevalent variant identified in thyroid carcinomas. This variant was identified mainly in FVPTC and can occur simultaneously with other variants. Whether the two non-synonymous variants are most likely to be relevant for pathogenesis of thyroid tumours or are random and more likely to be neutral (passengers) (31) needs further analysis.

Our findings and those from literature highlight the need for screening for mutations in 'non-hot spot' regions such as exon 6 of IDH1 in thyroid carcinomas; moreover, they substantiate the distinct distribution of IDH1 mutations in different tumour subtypes and populations. 
Regarding the synonymous variant, it was recently demonstrated that G105G was associated with inferior outcome in AML and higher expression of IDH1 mRNA (20). The authors suggested that G105G may alter IDH1 activity by altering RNA stability, folding and splicing. Likewise, G105G, the Y135Y synonymous variant identified for the first time in our study, may have clinical implications in thyroid tumours.

Comprehensive analysis of malignant gliomas revealed that there is a pattern of coincidental and exclusive mutations $(11,32)$. For example, IDH1 mutation co-occurs with TP53 mutations and is negatively correlated with the presence of PTEN, RB1, EGFR mutation (11) and BRAF rearrangement (23). Within this context, it is of interest to determine whether mutations previously identified in thyroid carcinomas co-occur with IDH1 or are mutually exclusive. We found that BRAF V600E mutation co-occurs in 5/18 IDH1-mutated thyroid carcinomas. RAS mutations co-occur in 2/18 IDH1-mutated thyroid carcinomas. Our findings suggested that RAS/RAF pathway and IDH1 mutations are not mutually exclusive. Therefore, the mechanism by which IDH1 acts in pathogenesis of thyroid carcinomas probably differs from those in brain tumours (33). Regarding the timing of IDH1 mutation in thyroid carcinomas, it remains to be established whether it occurs at relative early or late stages during tumour progression.

In addition to the biological implication, the identification of IDH1 mutations in thyroid carcinomas that are a common source of diagnostic error on fine-needle aspiration cytology such as FTC, its variant and FVPTC (34, 35), may have clinical implications. So far, mutations initially associated with pathogenesis of the malignant FTC were later described in the benign FTA $(6,7,36)$. However, further studies using defined groups on an independent panel of samples are essential to determine whether IDH1 mutations will potentially help to distinguish a benign from a malignant nodule.

Although no association of IDH1 mutation status was observed with most clinical features, there is a tendency to a higher frequency of IDH1 mutation in FTC and FVPTC. Remarkably, PTCs have been traditionally separated into variants, which may have distinct clinical and biological behaviour. Moreover, it has been suggested that FVPTC may be related more closely to FTC than to PTC (37). The finding that IDH1 is mutated in FVPTC brings new insights into the molecular events associated with pathogenesis of this tumour subtype, although further analysis is needed to determine IDH1 role in the pathogenesis of thyroid carcinomas.

In conclusion, our study identified novel IDH1 variants in thyroid carcinomas. IDH1 mutations were at higher frequencies in FTC and FVPTC. Studies using large panel of samples will clarify whether IDH1 can, to some extent, help to distinguish benign from malignant thyroid tumours. Although most of the mutations occurred in a conserved region of IDH1, further biochemical and functional studies are required to determine whether these mutations act similarly to the R132 mutation found in glioma and leukaemia. Finally, IDH1 may represent a novel target for therapy.

\section{Supplementary data}

This is linked to the online version of the paper at http://dx.doi.org/ 10.1530/EJE-10-0473.

\section{Declaration of interest}

The authors declare that there is no conflict of interest that could be perceived as prejudicing the impartiality of the research reported.

\section{Funding}

This work was supported by the São Paulo State Research Foundation (FAPESP) to J M Cerutti (grant numbers 05/60330-8 and 09/11257-7). $\mathrm{J}$ M Cerutti is an investigator of the Brazilian Research Council (CNPq). J P Hemerly and A U Bastos are scholars from FAPESP.

\section{Acknowledgements}

We thank Gregory J Riggins (Johns Hopkins University) for the editorial assistance.

\section{References}

1 Davies L \& Welch HG. Increasing incidence of thyroid cancer in the United States, 1973-2002. Journal of the American Medical Association 2006295 2164-2167. (doi:10.1001/jama.295.18. 2164)

2 Kimura ET, Nikiforova MN, Zhu Z, Knauf JA, Nikiforov YE \& Fagin JA. High prevalence of BRAF mutations in thyroid cancer: genetic evidence for constitutive activation of the RET/PTC-RASBRAF signaling pathway in papillary thyroid carcinoma. Cancer Research 200363 1454-1457.

3 Oler G \& Cerutti JM. High prevalence of BRAF mutation in a Brazilian cohort of patients with sporadic papillary thyroid carcinomas: correlation with more aggressive phenotype and decreased expression of iodide-metabolizing genes. Cancer 2009 115 972-980. (doi:10.1002/cncr.24118)

4 Fugazzola L, Mannavola D, Cirello V, Vannucchi G, Muzza M, Vicentini L \& Beck-Peccoz P. BRAF mutations in an Italian cohort of thyroid cancers. Clinical Endocrinology 200461 239-243. (doi:10.1111/j.1365-2265.2004.02089.x)

5 Kroll TG, Sarraf P, Pecciarini L, Chen CJ, Mueller E, Spiegelman BM \& Fletcher JA. PAX8-PPARgamma1 fusion oncogene in human thyroid carcinoma. Science 2000289 1357-1360. (doi:10.1126/ science.289.5483.1357)

6 Freitas BC \& Cerutti JM. Genetic markers differentiating follicular thyroid carcinoma from benign lesions. Molecular and Cellular Endocrinology $2010 \mathbf{3 2 1}$ 77-85. (doi:10.1016/j.mce. 2009.11.008)

7 Nakabashi CC, Guimaraes GS, Michaluart P Jr, Ward LS, Cerutti JM \& Maciel RM. The expression of PAX8-PPARgamma rearrangements is not specific to follicular thyroid carcinoma. Clinical Endocrinology 200461 280-282. (doi:10.1111/j.1365-2265.2004.02061.x)

8 Vasko V, Ferrand M, Di Cristofaro J, Carayon P, Henry JF \& de Micco C. Specific pattern of RAS oncogene mutations in follicular thyroid tumors. Journal of Clinical Endocrinology and Metabolism 200388 2745-2752. (doi:10.1210/jc.2002-021186)

9 Yeager N, Klein-Szanto A, Kimura S \& Di Cristofano A. Pten loss in the mouse thyroid causes goiter and follicular adenomas: insights 
into thyroid function and Cowden disease pathogenesis. Cancer Research 200767 959-966. (doi:10.1158/0008-5472. CAN-06-3524)

10 Sjoblom T, Jones S, Wood LD, Parsons DW, Lin J, Barber TD, Mandelker D, Leary RJ, Ptak J, Silliman N, Szabo S, Buckhaults P, Farrell C, Meeh P, Markowitz SD, Willis J, Dawson D, Willson JK, Gazdar AF, Hartigan J, Wu L, Liu C, Parmigiani G, Park BH, Bachman KE, Papadopoulos N, Vogelstein B, Kinzler KW \& Velculescu VE. The consensus coding sequences of human breast and colorectal cancers. Science $2006 \mathbf{3 1 4}$ 268-274. (doi:10. 1126/science.1133427)

11 Parsons DW, Jones S, Zhang X, Lin JC, Leary RJ, Angenendt P, Mankoo P, Carter H, Siu IM, Gallia GL, Olivi A, McLendon R, Rasheed BA, Keir S, Nikolskaya T, Nikolsky Y, Busam DA, Tekleab H, Diaz LA Jr, Hartigan J, Smith DR, Strausberg RL, Marie SK, Shinjo SM, Yan H, Riggins GJ, Bigner DD, Karchin R, Papadopoulos N, Parmigiani G, Vogelstein B, Velculescu VE \& Kinzler KW. An integrated genomic analysis of human glioblastoma multiforme. Science 2008321 1807-1812. (doi:10.1126/ science.1164382)

12 Iuliano R, Trapasso F, Stella A, Le Pera I, Melillo RM, Bruni P, Baldassarre G, Chiariotti L, Santoro M, Viglietto G \& Fusco A. Pivotal role of the RB family proteins in in vitro thyroid cell transformation. Experimental Cell Research 2000260 257-267. (doi:10.1006/excr.2000.5023)

13 Fagin JA, Matsuo K, Karmakar A, Chen DL, Tang SH \& Koeffler HP. High prevalence of mutations of the p53 gene in poorly differentiated human thyroid carcinomas. Journal of Clinical Investigation 199391 179-184. (doi:10.1172/JCI116168)

14 Garcia-Rostan G, Costa AM, Pereira-Castro I, Salvatore G, Hernandez R, Hermsem MJ, Herrero A, Fusco A, CameselleTeijeiro J \& Santoro M. Mutation of the PIK3CA gene in anaplastic thyroid cancer. Cancer Research 200565 10199-10207. (doi:10. 1158/0008-5472.CAN-04-4259)

15 Boltze C, Zack S, Quednow C, Bettge S, Roessner A \& SchneiderStock R. Hypermethylation of the CDKN2/p16INK4A promotor in thyroid carcinogenesis. Pathology, Research and Practice 2003199 399-404. (doi:10.1078/0344-0338-00436)

16 Yan H, Parsons DW, Jin G, McLendon R, Rasheed BA, Yuan W, Kos I, Batinic-Haberle I, Jones S, Riggins GJ, Friedman H, Friedman A, Reardon D, Herndon J, Kinzler KW, Velculescu VE, Vogelstein B \& Bigner DD. IDH1 and IDH2 mutations in gliomas. New England Journal of Medicine 2009360 765-773. (doi:10. 1056/NEJMoa0808710)

17 Bleeker FE, Lamba S, Leenstra S, Troost D, Hulsebos T, Vandertop WP, Frattini M, Molinari F, Knowles M, Cerrato A, Rodolfo M, Scarpa A, Felicioni L, Buttitta F, Malatesta S, Marchetti A \& Bardelli A. IDH1 mutations at residue p.R132 (IDH1(R132)) occur frequently in high-grade gliomas but not in other solid tumors. Human Mutation 200930 7-11. (doi:10. 1002/humu.20937)

18 Marcucci G, Maharry K, Wu YZ, Radmacher MD, Mrozek K, Margeson D, Holland KB, Whitman SP, Becker H, Schwind S, Metzeler KH, Powell BL, Carter TH, Kolitz JE, Wetzler M, Carroll AJ, Baer MR, Caligiuri MA, Larson RA \& Bloomfield CD. IDH1 and IDH2 gene mutations identify novel molecular subsets within de novo cytogenetically normal acute myeloid leukemia: a Cancer and Leukemia Group B study. Journal of Clinical Oncology 201028 2348-2355. (doi:10.1200/JCO.2009.27.3730)

19 Murugan AK, Bojdani E \& Xing M. Identification and functional characterization of isocitrate dehydrogenase 1 (IDH1) mutations in thyroid cancer. Biochemical and Biophysical Research Communications 2010393 555-559. (doi:10.1016/j.bbrc.2010.02.095)

20 Wagner K, Damm F, Gohring G, Gorlich K, Heuser M, Schafer I, Ottmann O, Lubbert M, Heit W, Kanz L, Schlimok G, Raghavachar AA, Fiedler W, Kirchner HH, Brugger W, Zucknick M, Schlegelberger B, Heil G, Ganser A \& Krauter J. Impact of IDH1 R132 mutations and an IDH1 single nucleotide polymorphism in cytogenetically normal acute myeloid leukemia: SNP rs11554137 is an adverse prognostic factor. Journal of Clinical Oncology 201028 2356-2364. (doi:10.1200/JCO.2009.27.6899)
21 Xu X, Zhao J, Xu Z, Peng B, Huang Q, Arnold E \& Ding J. Structures of human cytosolic NADP-dependent isocitrate dehydrogenase reveal a novel self-regulatory mechanism of activity. Journal of Biological Chemistry 2004279 33946-33957. (doi:10.1074/jbc. M404298200)

22 Dang L, White DW, Gross S, Bennett BD, Bittinger MA, Driggers EM, Fantin VR, Jang HG, Jin S, Keenan MC, Marks KM, Prins RM, Ward PS, Yen KE, Liau LM, Rabinowitz JD, Cantley LC, Thompson CB, Vander Heiden MG \& Su SM. Cancer-associated IDH1 mutations produce 2-hydroxyglutarate. Nature $2009 \mathbf{4 6 2}$ 739-744. (doi:10.1038/nature08617)

23 Korshunov A, Meyer J, Capper D, Christians A, Remke M, Witt H, Pfister S, von Deimling A \& Hartmann C. Combined molecular analysis of BRAF and IDH1 distinguishes pilocytic astrocytoma from diffuse astrocytoma. Acta Neuropathologica 2009118 401-405. (doi:10.1007/s00401-009-0550-z)

24 Oler G, Ebina KN, Michaluart P Jr, Kimura ET \& Cerutti J. Investigation of BRAF mutation in a series of papillary thyroid carcinoma and matched-lymph node metastasis reveals a new mutation in metastasis. Clinical Endocrinology 200562 509-511. (doi:10.1111/j.1365-2265.2005.02235.x)

25 Mardis ER, Ding L, Dooling DJ, Larson DE, McLellan MD, Chen K, Koboldt DC, Fulton RS, Delehaunty KD, McGrath SD, Fulton LA, Locke DP, Magrini VJ, Abbott RM, Vickery TL, Reed JS, Robinson JS, Wylie T, Smith SM, Carmichael L, Eldred JM, Harris CC, Walker J, Peck JB, Du F, Dukes AF, Sanderson GE, Brummett AM, Clark E, McMichael JF, Meyer RJ, Schindler JK, Pohl CS, Wallis JW, Shi X, Lin L, Schmidt H, Tang Y, Haipek C, Wiechert ME, Ivy JV, Kalicki J, Elliott G, Ries RE, Payton JE, Westervelt P, Tomasson MH, Watson MA, Baty J, Heath S, Shannon WD, Nagarajan R, Link DC, Walter MJ, Graubert TA, DiPersio JF, Wilson RK \& Ley TJ. Recurring mutations found by sequencing an acute myeloid leukemia genome. New England Journal of Medicine 2009361 1058-1066. (doi:10.1056/ NEJMoa0903840)

26 Zhao S, Lin Y, Xu W, Jiang W, Zha Z, Wang P, Yu W, Li Z, Gong L, Peng Y, Ding J, Lei Q, Guan KL \& Xiong Y. Glioma-derived mutations in IDH1 dominantly inhibit IDH1 catalytic activity and induce HIF-1alpha. Science 2009324 261-265. (doi:10.1126/ science.1170944)

27 Frezza C, Tennant DA \& Gottlieb E. IDH1 mutations in gliomas: when an enzyme loses its grip. Cancer Cell 201017 7-9. (doi:10. 1016/j.ccr.2009.12.031)

28 Gross S, Cairns RA, Minden MD, Driggers EM, Bittinger MA, Jang HG, Sasaki M, Jin S, Schenkein DP, Su SM, Dang L, Fantin VR \& Mak TW. Cancer-associated metabolite 2-hydroxyglutarate accumulates in acute myelogenous leukemia with isocitrate dehydrogenase 1 and 2 mutations. Journal of Experimental Medicine 2010207 339-344. (doi:10.1084/jem.20092506)

29 Ward PS, Patel J, Wise DR, Abdel-Wahab O, Bennett BD, Coller HA, Cross JR, Fantin VR, Hedvat CV, Perl AE, Rabinowitz JD, Carroll M, Su SM, Sharp KA, Levine RL \& Thompson CB. The common feature of leukemia-associated $\mathrm{IDH} 1$ and $\mathrm{IDH} 2$ mutations is a neomorphic enzyme activity converting alpha-ketoglutarate to 2-hydroxyglutarate. Cancer Cell 201017 225-234. (doi:10.1016/ j.ccr.2010.01.020)

30 Varfolomeev SD, Uporov IV \& Fedorov EV. Bioinformatics and molecular modeling in chemical enzymology. Active sites of hydrolases. Biochemistry (Moscow) 200267 1099-1108. (doi:10. 1023/A:1020907122341)

31 Merlo LM, Pepper JW, Reid BJ \& Maley CC. Cancer as an evolutionary and ecological process. Nature Reviews. Cancer 20066 924-935. (doi:10.1038/nrc2013)

32 Watanabe T, Vital A, Nobusawa S, Kleihues P \& Ohgaki H. Selective acquisition of IDH1 R132C mutations in astrocytomas associated with Li-Fraumeni syndrome. Acta Neuropathologica 2009117 653-656. (doi:10.1007/s00401-009-0528-x)

33 van den Bent MJ, Dubbink HJ, Marie Y, Brandes AA, Taphoorn MJ, Wesseling P, Frenay M, Tijssen CC, Lacombe D, Idbaih A, van Marion R, Kros JM, Dinjens WN, Gorlia T \& Sanson M. IDH1 and IDH2 mutations are prognostic but not predictive for 
outcome in anaplastic oligodendroglial tumors: a Report of the European Organization for Research and Treatment of Cancer Brain Tumor Group. Clinical Cancer Research $2010161597-$ 1604. (doi:10.1158/1078-0432.CCR-09-2902)

34 Cerutti JM, Latini FR, Nakabashi C, Delcelo R, Andrade VP, Amadei MJ, Maciel RM, Hojaij FC, Hollis D, Shoemaker J \& Riggins GJ. Diagnosis of suspicious thyroid nodules using four protein biomarkers. Clinical Cancer Research $2006123311-3318$. (doi:10.1158/1078-0432.CCR-05-2226)

35 Cerutti JM, Delcelo R, Amadei MJ, Nakabashi C, Maciel RM, Peterson B, Shoemaker J \& Riggins GJ. A preoperative diagnostic test that distinguishes benign from malignant thyroid carcinoma based on gene expression. Journal of Clinical Investigation 2004 113 1234-1242. (doi:10.1172/JCI19617)

36 Cerutti JM. Nodule diagnosed as follicular patterned lesion: are biomarkers the promise? Arquivos Brasileiros de Endocrinologia e Metabologia $200751832-842$.

37 Wreesmann VB, Sieczka EM, Socci ND, Hezel M, Belbin TJ, Childs G, Patel SG, Patel KN, Tallini G, Prystowsky M, Shaha AR, Kraus D, Shah JP, Rao PH, Ghossein R \& Singh B. Genome-wide profiling of papillary thyroid cancer identifies MUC1 as an independent prognostic marker. Cancer Research 200464 3780-3789. (doi:10.1158/0008-5472.CAN-03-1460)

38 Ho PA, Alonzo TA, Kopecky KJ, Miller KL, Kuhn J, Zeng R, Gerbing RB, Raimondi SC, Hirsch BA, Oehler V, Hurwitz CA, Franklin JL, Gamis AS, Petersdorf SH, Anderson JE, Reaman GH, Baker LH, Willman CL, Bernstein ID, Radich JP, Appelbaum FR, Stirewalt DL \& Meshinchi S. Molecular alterations of the IDH1 gene in AML: a Children's Oncology Group and Southwest Oncology Group study. Leukemia 201024 909-913. (doi:10. 1038/leu.2010.56)

39 Knudsen B \& Miyamoto MM. Sequence alignments and pair hidden Markov models using evolutionary history. Journal of Molecular Biology 2003333 453-460. (doi:10.1016/j.jmb.2003. $08.015)$

Received 10 August 2010

Accepted 11 August 2010 